\title{
Abordagem do solo no ensino médio: concepções e práticas nas aulas de Geografia ${ }^{1}$
}

\author{
Approaching soil in high school: conceptions and \\ practices in Geography classes
}

\author{
Josiane Costalonga Andrade ${ }^{a}$ \\ Jully Gabriela Retzlaf Oliveira ${ }^{\mathrm{b}}$
}

\author{
a Licenciada em Geografia pela Universidade Estadual do Norte do Paraná (Uenp). \\ E-mail: acir_jo@hotmail.com \\ ${ }^{\text {b }}$ Professora doutora adjunta do Departamento de Geografia da Universidade Estadual do Norte \\ do Paraná (Uenp). \\ E-mail: jullyoliveira@uenp.edu.br
}

\begin{abstract}
O solo é um recurso natural, base para desenvolver várias atividades antrópicas. Desta forma faz-se necessário estudá-lo, pois seu uso inadequado pode acarretar problemas socioambientais. Objetivamos analisar a abordagem do solo e suas propriedades no Ensino Médio, desde o entendimento e percepção dos alunos sobre o tema até as aulas e práticas de ensino voltadas à explicação deste conteúdo na Geografia escolar. Metodologicamente, trata-se de estudo de caso de um grupo de alunos do $3^{\circ}$ ano do ensino médio de uma escola pública de Cornélio Procópio/PR, compreendendo revisão bibliográfica sobre o solo e suas propriedades; aplicação de questionário aos estudantes do $3^{\circ}$ ano do Ensino Médio antes das aulas e práticas de ensino voltadas à abordagem do solo; abordagem do conteúdo de solo e suas propriedades em sala de aula; aplicação do questionário após as aulas e práticas de ensino e; análise dos resultados. Aplicar aulas e práticas de ensino via oficinas e experimentos para explicar o solo e suas propriedades contribuiu para melhorar o entendimento dos alunos sobre o assunto. Estes passaram a entender o solo como camada superficial da Terra resultante de vários fatores de formação, constituído de componentes minerais e orgânicos, e a diferenciá-lo em suas propriedades.
\end{abstract}

Palavras-chave: recurso natural, prática de ensino, Geografia Física.

\begin{abstract}
The soil is a natural resource, the basis for various human activities. Given that its improper use can cause socio-environmental problems, studies on soil are performed. We analyzed the approach to soil and its properties in high school by verifying the understanding and perception of students on the subject, classes themselves, and teaching practices related to geography in school. This case study included a group of students from the 3rd year of high school in a public school in Cornélio Procópio, Paraná, comprising a bibliographic review of the soil and its properties; the application of a questionnaire to students in the 3rd year of high school before classes and teaching practices focused on the soil; the approach to soil content and its properties in the classroom; the application of the questionnaire after classes and teaching practices; and analysis of results. Applying classes and teaching practices via workshops and experiments to explain the soil and its properties contributed to improving the students' understanding of the subject. They came to understand the soil as a superficial layer of the Earth resulting from various formative factors consisting of mineral and organic components, and learned to differentiate its properties.
\end{abstract}

Keywords: natural resource, teaching practice, Physical Geography.

1 Artigo extraído do Trabalho de Conclusão de Curso apresentado no curso de Geografia da Universidade Estadual do Norte do Paraná. 


\section{INTRODUÇÃO}

O ensino de Geografia deve propiciar ao aluno a compreensão do espaço geográfico em sua concretude (CAVALCANTI, 2002), ou seja, alfabetizar o aluno na leitura do espaço geográfico, em suas diversas escalas e configurações. O estudo dos fenômenos naturais, sua regularidade e possibilidade de previsão pelo homem torna-se extremamente importante para compreender a organização do espaço geográfico. A natureza tem seus mecanismos e leis que podem ser estudados em sua regularidade e tempos próprios, sendo fundamental tratar os componentes da natureza nas suas especificidades, como é o caso do solo.

A compreensão do solo e de sua dinâmica é muito importante, pois este recurso natural fundamenta a vida no planeta pelas funções que lhe são inerentes e influencia direta e indiretamente várias atividades antrópicas como: produção de alimentos, fibras e energia; sustentação de cidades e infraestrutura de transportes; fonte de matérias-primas e biodiversidade; suporte dos grandes ciclos biogeoquímicos; filtração e transformação de resíduos; atuação como reservatório de água e, ainda, manutenção do registro histórico da evolução do planeta (LEPSCH, 2002).

Mesmo com toda essa importância, o solo não tem sido bem cuidado. Segundo o relatório da Food and Agriculture Organization of the United Nations (FAO) de 2015 (EMBRAPA, 2015) somente a erosão elimina de 25 a 40 bilhões de toneladas de solo por ano, reduzindo significativamente a produtividade das culturas e capacidade de armazenar carbono, nutrientes e água. $\mathrm{Na}$ América Latina o cenário também é preocupante: "Cerca de $50 \%$ dos solos latinoamericanos estão sofrendo algum tipo de degradação. No Brasil, os principais problemas encontrados são erosão, perda de carbono orgânico, e desequilíbrio de nutrientes" (EMBRAPA, 2015).

Portanto, torna-se fundamental a abordagem adequada do solo nas aulas de Geografia do Ensino Médio, destacando seu funcionamento, constituição e principalmente suas propriedades físicas e características morfológicas. Estudar e compreender as propriedades físicas do solo torna-se importante uma vez que estas influenciam profundamente não apenas o modo como ele funciona em um ecossistema, como também a melhor forma de manejá-lo (BRADY; WEIL, 2013). Os autores argumentam que o sucesso ou o fracasso de projetos, tanto agrícolas, quanto de engenharia civil dependem, com frequência, das propriedades físicas do solo a ser utilizado, influenciando o crescimento das espécies, a dinâmica da água e também dos solutos.

Este artigo tem por objetivo analisar a abordagem do solo e suas propriedades nas aulas de Geografia do Ensino Médio, compreendendo desde o entendimento e a percepção dos alunos sobre o tema, até as aulas e práticas de ensino voltadas à explicação deste conteúdo na Geografia Escolar.

\section{O solo e suas propriedades}

O termo solo origina-se do latim: solum (suporte, superfície, base). A concepção de solo depende do conhecimento adquirido a seu respeito, de acordo com o modelo conceitual que ele representa nas diferentes atividades humanas. Assim, o solo é definido como agregado não cimentado de grãos minerais e matéria orgânica decomposta (partículas sólidas), com líquido e gás nos espaços vazios entre as partículas sólidas (DAS, 2007, p. 1).

Entre os diversos conceitos de solo destacam-se: o solo como meio para o desenvolvimento das plantas; o solo como regolito; o solo como corpo natural organizado; o solo como sistema aberto. O solo é um elemento da paisagem, organizado, com vida própria e com permanentes entradas e saídas de matéria, sendo resultado de diferentes formações geológicas, de variados tipos de clima, de muitas formações vegetais, de uma variedade de formas de relevo, do fator tempo e, ainda, das mais variadas formas de uso e ocupação humana (EMBRAPA, 2013).

Segundo a Empresa Brasileira de Pesquisa Agropecuária (EMBRAPA, 2013) os solos são constituídos de água, ar, material mineral e orgânico, contendo ainda organismos vivos. Servem como meio natural para o crescimento das plantas, e é acima deles que construímos nossas casas, edifícios, estradas etc. É acima deles que se vive. Existem diferentes tipos ou classes de solos na natureza (classes de solos é o termo técnico para se referir aos diferentes tipos de solos).

O solo é a coleção de corpos naturais dinâmicos, que contém matéria viva e resulta da ação do clima e de organismos sobre um material de origem, cuja transformação em solo se realiza durante certo tempo e é influenciada pelo tipo de relevo. Assim, sob a ação de intemperismo químico, físico e biológico o solo começa a se formar, surgindo os horizontes, que são seções paralelas à superfície que diferem das seções adjacentes em suas propriedades morfológicas, físicas, químicas, 
mineralógicas e biológicas, originando o perfil de solo, que é seção vertical do terreno desde a superfície até o material de origem (KER et al., 2012).

Entre os solos e dentro de cada um deles, os horizontes podem diferir entre si nas propriedades, tais como: constituição, cor, textura, estrutura, cerosidade, porosidade, consistência, cimentação, pedoclima e pedoforma (RESENDE et al., 2007), feições morfológicas visíveis a olho nu ou sensíveis ao tato (LEPSCH, 2011).

A cor do solo é uma das feições pedológicas mais notadas, por ser de fácil visualização (LEPSCH, 2002). Os solos apresentam ampla variedade de cores, que podem ser diferentes de um lugar para outro na paisagem, assim como variar em profundidade entre os horizontes do solo, ou mesmo dentro de um único horizonte ou agregado do solo. Os principais fatores que influenciam sua cor são: o conteúdo de matéria orgânica; o teor de água e a presença e o estado de oxidação do ferro e de manganês (BRADY; WEIL, 2013). Os solos acinzentados indicam excesso de água no perfil; os solos escuros indicam altos teores de restos orgânicos, já os solos amarelados (goethita) e avermelhados (hematita) se relacionam a solos com altos teores de ferro $(\mathrm{Fe})$. Desta forma, a cor do solo é obtida comparando-se uma amostra de solo úmido com os padrões da carta de Munsell (LEPSCH, 2002).

A textura refere-se à proporção relativa das diversas frações granulométricas que compõem o solo, especificamente às proporções de areia, silte e argila (KER et al., 2012). Uma amostra de solo é considerada arenosa se possuir 85\% de areia; argilosa se houver mais de 35\% de argila e média se tiver porções equilibradas de areia, silte e argila (LEPSCH, 2002).

A estrutura é o resultado do arranjamento das partículas primárias do solo (areia, silte e argila) em agregados (KER et al., 2012), ou seja, refere-se ao tamanho, forma e aspecto do conjunto dos agregados que aparecem naturalmente no solo (LEPSCH, 2002).

A cerosidade diz respeito ao revestimento, quase sempre de argila acumulada sobre agregados, que aparenta ser uma espécie de "filme" do material, o qual apresenta um brilho com aspecto ceroso ou lustroso (LEPSCH, 2011).

A porosidade refere-se ao espaço poroso do solo ocupado por ar ou água e está relacionada à estrutura $\mathrm{e}$ textura do solo, tendo o solo argiloso maior quantidade de microporos e o arenoso maior quantidade de macroporos (RESENDE et al., 2007).
A consistência do solo refere-se à resistência do torrão de solo a alguma força que tende a rompê-lo, sendo definida pela resistência que o solo apresenta para ser deformado ou rompido quando um estresse lhe é aplicado (LEPSCH, 2011).

A cimentação refere-se à união das partículas do solo por um agente cimentante, podendo formar camadas impermeáveis às raízes e à água. O pedoclima refere-se ao regime hídrico e término do solo e, no Brasil, a vegetação tem sido usada para caracterização pedoclimática geral. Já a pedoforma se relaciona à forma externa do solo ligada à topografia, situando-se nas áreas planas os solos mais velhos e nas áreas acidentadas os solos mais jovens (RESENDE et al., 2007).

\section{MATERIAIS E MÉTODOS}

Metodologicamente, esta pesquisa é um estudo de caso com um grupo de alunos do $3^{\circ}$ ano do Ensino Médio (26 alunos, período matutino) do Colégio Estadual Zulmira Marchesi da Silva (Ideb 4,8 em 2017), localizado na área central da cidade de Cornélio Procópio, estado do Paraná.

O estudo de caso é um tipo de pesquisa no qual um caso individual é estudado em profundidade para se obter uma compreensão ampliada sobre outros casos similares, possibilitando a criação de um modelo ou de novos procedimentos padrão (CAJUEIRO, 2013).

Os alunos foram escolhidos por estarem terminando a educação básica e afirmarem ter pouco conhecimento sobre o solo e suas propriedades. Para tanto, foram necessárias cinco fases distintas: 1) leitura bibliográfica e revisão teórica sobre solo e suas propriedades; 2) aplicação do Questionário 1 aos estudantes do $3^{\circ}$ ano do Ensino Médio, no segundo semestre de 2017, antes das aulas e práticas de ensino voltadas para a abordagem do solo; 3) abordagem do conteúdo de solo e suas propriedades nas aulas de Geografia por meio de aulas expositivas sobre o assunto e desenvolvimento de oficinas e experimentos (as aulas foram dadas durante a realização do Estágio Curricular Supervisionado em Geografia II pela autora Josiane C. Andrade no curso de Geografia da Universidade Estadual do Norte do Paraná); 4) aplicação do Questionário 2 (na mesma turma em que foi aplicado o Questionário 1 após as aulas e práticas de ensino e 5) análise dos resultados obtidos. 
O Questionário 1 foi aplicado no dia 14 de agosto de 2017 com 19 alunos (os alunos foram identificados com números de 1 a 19), antes da realização das aulas sobre o solo. O Questionário 2 foi aplicado no dia $1^{\circ}$ de setembro de 2017 com os mesmos alunos do Questionário 1. Nesse dia, porém, a totalidade dos discentes da turma estava presente, 26 respondentes (estes foram identificados com os números de 20 a 45), e o questionário foi aplicado após a realização de aulas e práticas de ensino voltadas para a abordagem do solo e suas propriedades.

Os questionários 1 e 2 foram compostos das seguintes questões:

1. "Você poderia explicar o que é solo?"

2. "Todos os solos são iguais?"

3. "Você poderia apontar o que diferencia um solo de outro?"

4. "Você poderia citar as propriedades do solo?"

A abordagem do conteúdo de "solo e suas propriedades" ocorreu em duas semanas, utilizando quatro aulas para explicação do tema, realizadas nos dias 21 e 28 de agosto de 2017 no $3^{\circ}$ ano do Ensino Médio.

No decorrer das aulas utilizou-se o método expositivo para explicação teórica do conteúdo, com demonstração didática do tema por meio da realização de práticas de ensino como oficinas e experimentos sobre algumas propriedades do solo: cor, textura, porosidade e consistência. Estas foram escolhidas por serem visíveis e sensíveis ao tato.

O método de exposição pelo professor consiste em explicar um novo conteúdo usando explanação verbal, demonstração, ilustração, exemplificação (LIBÂNEO, 1994). Segundo o autor, a demonstração é a forma de representar fenômenos e processos que ocorrem na realidade, seja por meio de trabalhos de campo, exposição de slides, oficinas, realização de experimento, maquete etc.

Andrade e Massabni (2011, p. 840) definem práticas pedagógicas como "tarefas educativas que requerem do aluno a experiência direta com o material presente fisicamente, com o fenômeno e com dados brutos obtidos do mundo natural ou social”. Nisso, a ação do aluno deve ocorrer por meio da experiência física, seja desenvolvendo a tarefa manualmente, seja observando o professor em uma demonstração, desde que, na tarefa, se apresente o objeto materialmente.

\section{Resultados E Discussão}

\section{Práticas de ensino voltadas para a abordagem do solo e suas propriedades nas aulas de Geografia do Ensino Médio: um relato de experiência}

No dia 21 de agosto de 2017 foi realizada uma aula expositiva sobre o conceito de solo e suas propriedades físicas. Após a aula teórica, para explicação da cor do solo foi desenvolvida uma oficina de cor do solo, com a construção de uma paleta de cores do solo, utilizando-se os seguintes materiais: amostras de solos de cores diferentes secas e peneiradas, cola branca, água limpa, copinho de café para dosagem do material e preparo da tinta; pincéis para artesanato e papel para a pintura da paleta de cores do solo. Para construção da paleta de cores do solo, os alunos incialmente prepararam algumas tintas de terra, misturando duas partes de terra peneirada (usando a medida do copinho de café), duas partes de água e uma parte de cola branca, utilizando a metodologia proposta por Capeche (2010). $\mathrm{Na}$ sequência os alunos montaram individualmente sua paleta de cores do solo (Figura 1), pintando a área delimitada com a tinta de solo produzida. Esta atividade possibilitou aos alunos compreender melhor as diferentes cores de solo existentes, bem como os diferentes agentes pigmentantes.

No dia 28 de agosto de 2017, para compreender a textura do solo foram desenvolvidas duas atividades: 1) Ficha de textura do solo e 2) Elaboração de amostras de terra arenosa e solo argilosa. Antes do desenvolvimento das atividades os alunos conheceram e sentiram os diversos tamanhos de partículas constituintes do solo (cascalho, areia grossa, areia fina, silte e argila) (Figura 2). Para montagem da ficha de textura do solo foram utilizadas amostras secas de cascalho, areia grossa, areia fina, silte, uma folha com a ficha de textura do solo (Figura 3) e cola branca para fixação das frações granulométricas na ficha (Figura 4). Com esta atividade foi possível que os alunos verificassem os diversos materiais constituintes do solo, sentindo a aspereza com a areia, a sedosidade com o silte e a pegajosidade com a argila. 
Figura 1. Paletas de cores do solo elaboradas pelos alunos.

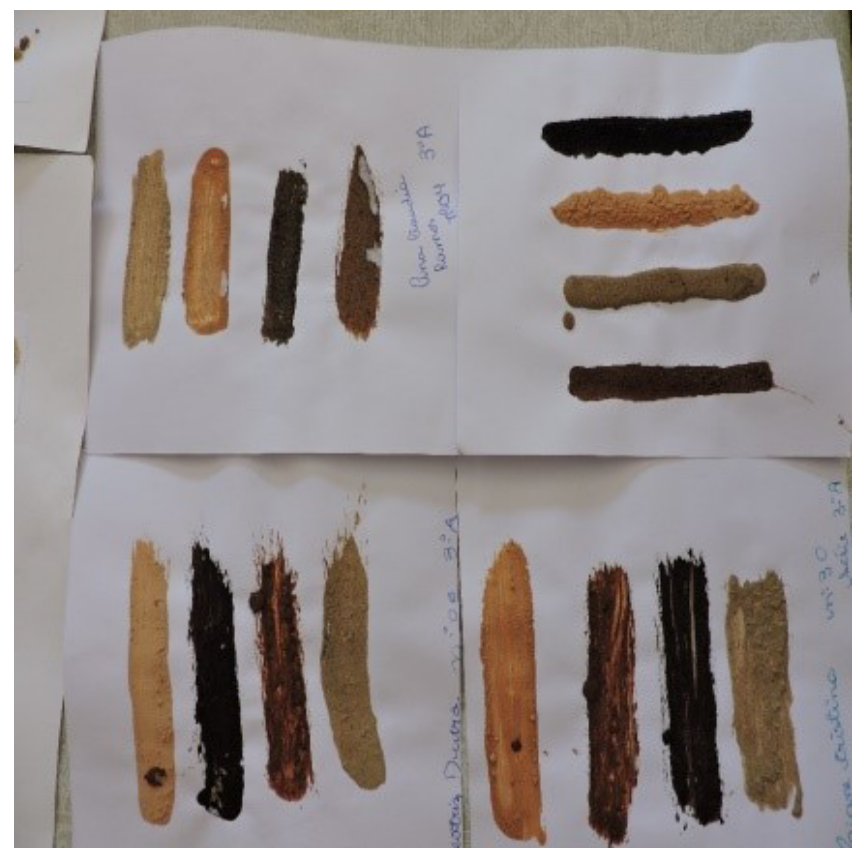

Fonte: Andrade (2017).

Figura 2. Alunos identificando pelo tato as frações granulométricas do solo.

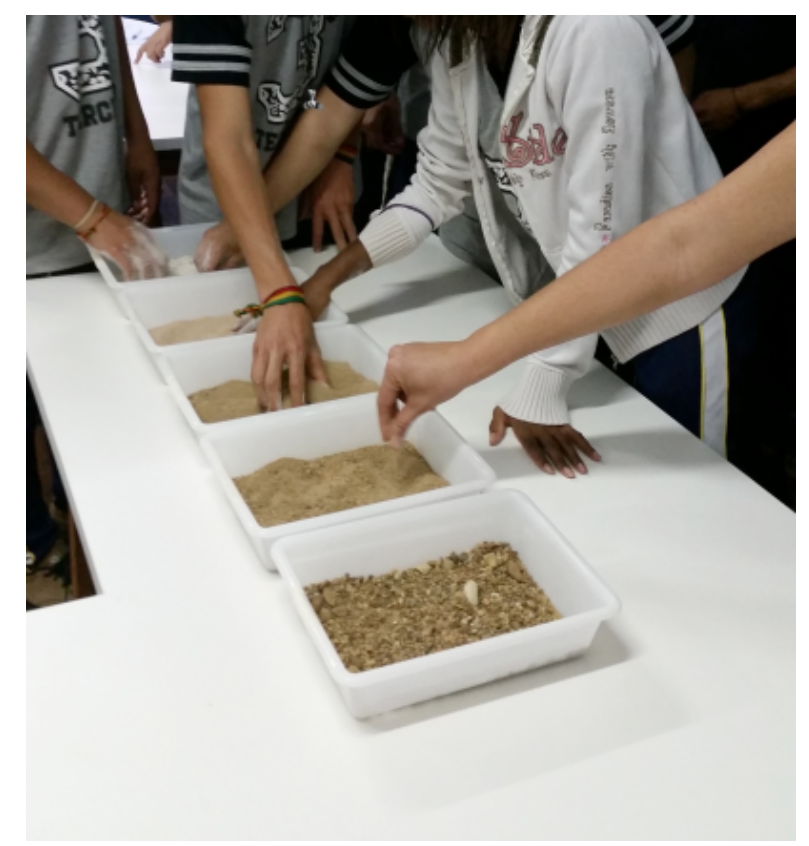

Fonte: Andrade (2017).
Após a realização da ficha de textura do solo, os alunos elaboraram amostras de terras de diferentes texturas, sendo: terra arenosa e terra argilosa (Figura 5). Para a terra arenosa foram usados dois copinhos (de café) com pedrinhas, quatro copinhos (de café) com areia grossa, cinco copinhos (de café) com areia fina, um copinho (de café) com argila (previamente seca e triturada), de um (KER et al., 2012) a dois copinhos (de café) com água e uma bacia de plástico para fazer a mistura do solo. Para a terra argilosa foi usado um copinho (de café) com areia grossa, um copinho (de café) com areia fina, sete copinhos (de café) com argila (previamente seca e triturada), de um a dois copinhos (de café) com água e uma bacia de plástico para fazer a mistura do solo, seguindo a metodologia proposta por Macanhão e Lima (2005). Com as amostras das terras produzidas, os alunos fizeram o "Teste da Bolinha", que consiste em pegar uma pequena porção de solo úmido, criando uma "bolinha" de $3 \mathrm{~cm}$ de diâmetro para em seguida deixar a bolinha cair; se ela se destruir a textura é arenosa, se a bolinha não se destruir e formar um cilindro a textura é argilosa, seguindo a metodologia proposta por Venturi (2009).

Figura 3. Modelo de ficha de textura do solo.

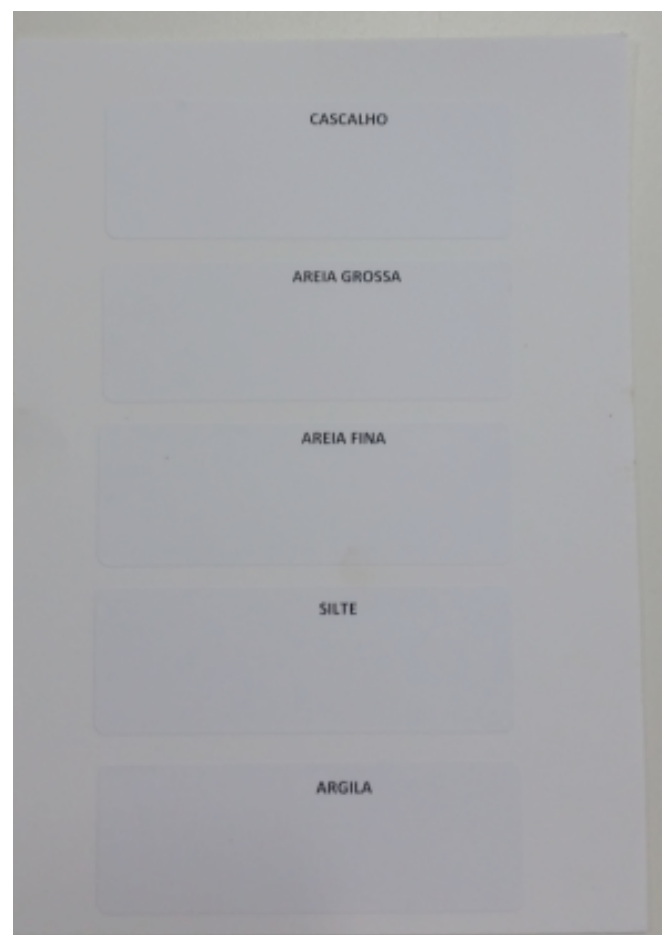

Fonte: Andrade (2017). 
Figura 4. Ficha de textura do solo elaborada por um aluno.

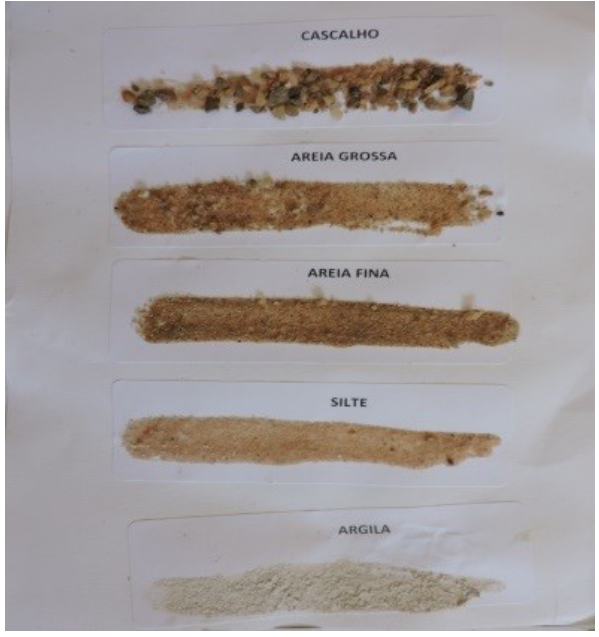

Fonte: Andrade (2017).

Figura 5. Elaboração da terra arenosa e argilosa.

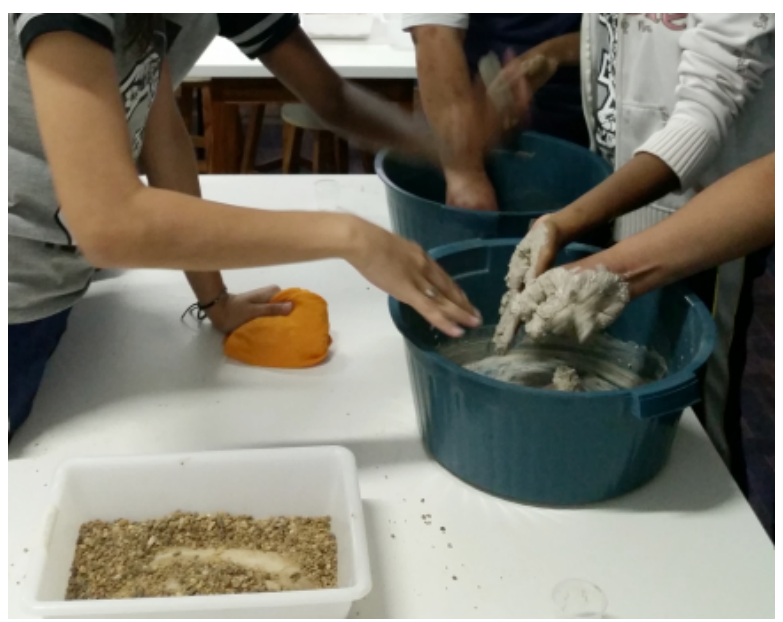

Fonte: Andrade (2017).

Para explicar a porosidade do solo arenoso e argiloso foi realizado um experimento de infiltração e retenção de água no solo. No experimento foram usados dois copos de uma amostra seca e triturada de um solo arenoso (solo coletado na cidade de Tibagi/PR); dois copos de uma amostra seca e triturada de um solo argiloso (solo coletado na cidade de Cornélio Procópio/PR); duas garrafas plásticas descartáveis transparentes (de refrigerante tipo PET de $2 \mathrm{~L}$ ); pedaços de tecido (usado para segurar o solo na boca da garrafa); barbante (para prender o tecido em torno da boca da garrafa) e água, seguindo a metodologia proposta por Yoshioka e Lima (2017). Em cada garrafa PET foi colocada a mesma quantidade de amostra de solo (uma garrafa com solo arenoso e uma garrafa com solo argiloso) e despejada a mesma quantidade de água para verificar a infiltração e retenção de água no solo arenoso e no solo argiloso de acordo com sua porosidade (figura 6), sendo possível observar maior infiltração da água no solo arenoso com maior quantidade de macroporos e maior retenção de água no solo argiloso, causada pela maior quantidade de microporos.

Figura 6. Montagem do experimento de infiltração e retenção de água no solo.

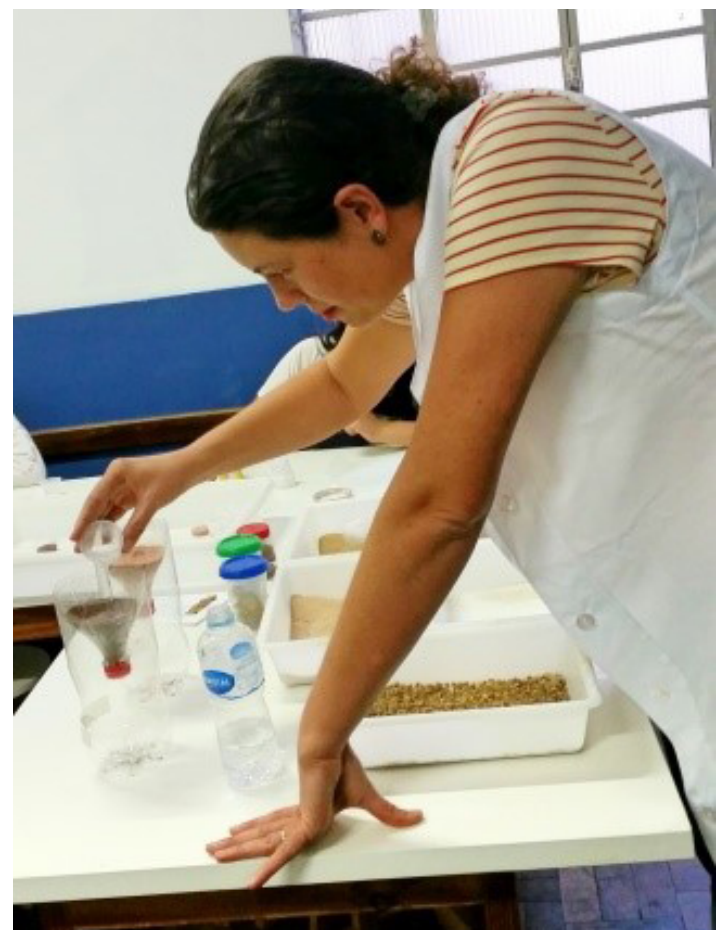

Fonte: Andrade (2017).

\section{A concepção dos alunos do Ensino Médio sobre solo antes e depois da abordagem em sala de aula}

A seguir serão relatados e analisados os dados obtidos com a aplicação de dois questionários aos estudantes do $3^{\circ}$ ano do Ensino Médio. Na questão 1, "Você poderia explicar o que é Solo?", a maioria dos alunos o definiu como meio para a agricultura, camada superficial da Terra e chão onde pisamos, sendo muito superficiais em suas respostas (Gráfico 1), por exemplo: Aluno 1: "é a camada mais superficial da crosta, é a camada que recobre as rochas"; e Aluno 2: "é a camada superficial da crosta". 
Gráfico 1. Agrupamentos das respostas dos estudantes para a pergunta "O que é solo" antes da aula no Questionário 1.

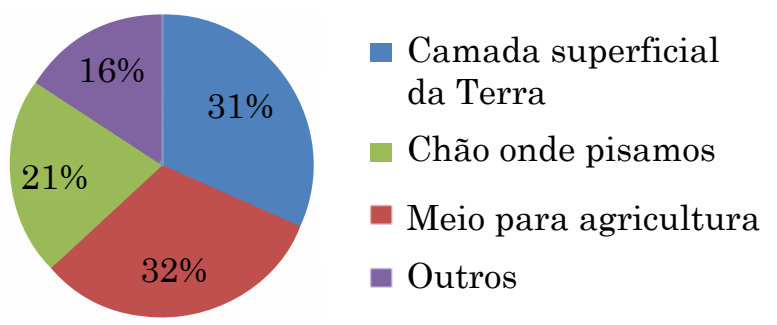

Fonte: Andrade (2017).

Segundo Lepsch (2002), não é tudo que recobre a superfície que se pode chamar de solo, pois de acordo com a Pedologia, o solo é a coleção de corpos naturais dinâmicos, que contém matéria viva e resulta da ação do clima e de organismos sobre um material de origem, cuja transformação em solo se realiza durante certo tempo e é influenciada pelo tipo de relevo.

Após exposição teórica e aula prática, foi possível observar na questão 1 que a maioria dos alunos ainda compreendia o solo como camada superficial que recobre a Terra, porém uma parcela deles passou a ver o solo não só como um material superficial, mas como um produto originado a partir de alguns fatores de formação e composto por material mineral e orgânico (Gráfico 2), a exemplo das respostas: Aluno 29: "camada mais superficial da Terra constituído por material mineral (areia, argila) e matéria orgânica"; e Aluno 30: "solo é toda extensão da crosta terrestre, resultado da degradação de rochas pelo clima, relevo, temperatura, chuva, organismos etc".

Na questão 2, “Todos os solos são iguais?" (sim ou não), todos os alunos assinalaram não, compreendendo que os solos são diferentes, tanto antes como após a abordagem de solo nas aulas.

Gráfico 2. Agrupamentos das respostas dos estudantes para a pergunta "O que é solo" após a aula e práticas no Questionário 2.

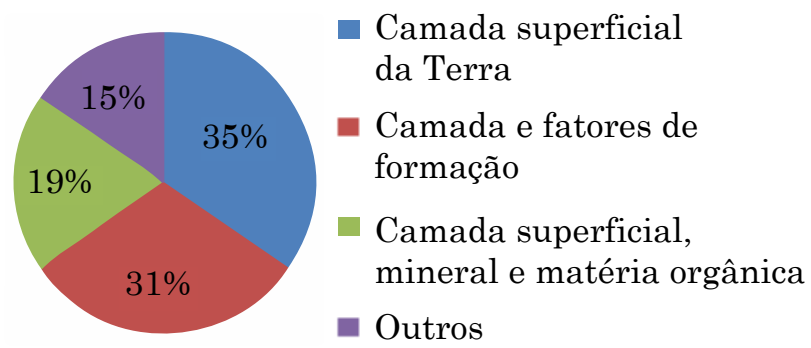

Fonte: Andrade (2017).
Já na questão 3, "Você poderia apontar o que diferencia de um solo para o outro?", constatou-se que a maioria dos alunos antes das aulas, $32 \%$, disseram que a diferença de um solo para outro estaria relacionada à fertilidade. Isso ocorreu provavelmente devido à pergunta sobre o que é solo, à qual a maioria respondeu que se tratava de um meio para a agricultura. Por outro lado, foi grande o número de alunos que não souberam $(26 \%)$ ou não responderam a questão por falta de conhecimento sobre o assunto (Gráfico 3). Diante do levantado, observa-se que os alunos não têm noção exata do que diferencia um solo do outro.

Gráfico 3. Concepção dos alunos do que diferencia um solo do outro antes da aula no Questionário 1.

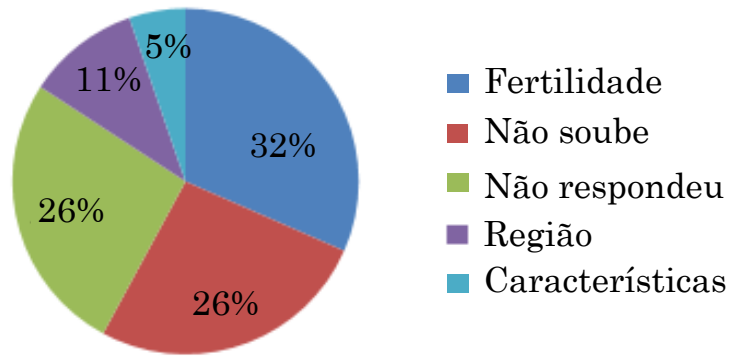

Fonte: Andrade (2017).

Na sequência, após a abordagem do solo nas aulas, observou-se que a maioria dos alunos, 89\% (Gráfico 4), consegue identificar o que diferencia um solo do outro apontando em suas respostas as propriedades do solo, como cor, textura, entre outras. Aqui, nota-se que quase todas as respostas fizeram referência à textura. Isso provavelmente se deve às atividades de textura do solo realizadas no dia 28 de agosto, conforme respostas a seguir: Aluno 34: "cor de seus componentes, a sua resistência e sua textura"; Aluno 35: "que um pode ser mais grosso ou fino, mais consistente, outros absorvem mais a água".

Na questão 4, "Você poderia citar as propriedades do solo?", foi possível verificar que grande parte dos alunos, $48 \%$, responderam errado à questão antes das aulas (Gráfico 5), mostrando pouco conhecimento das propriedades do solo. Porém, após as aulas, nota-se que os alunos compreenderam quais são as propriedades do solo, citando-as (cor, textura, estrutura, porosidade e consistência) (Gráfico 6). Dentre as propriedades mais citadas, destacam-se a cor e a textura, presentes em todas as respostas, sendo provavelmente resultado das práticas de ensino desenvolvidas em sala: paleta de cores do solo, ficha de textura de solo e elaboração de amostras 
de solo de textura arenosa e argilosa, mais uma vez demonstrando e ressaltando a importância da prática de ensino no processo de aprendizagem que, se utilizada adequadamente, trará ao aluno uma compreensão melhor e mais ampla do conteúdo trabalhado, corroborando uma aprendizagem significativa.

Gráfico 4. Concepção dos alunos sobre o que diferencia um solo do outro após aula e práticas de ensino no Questionário 2.

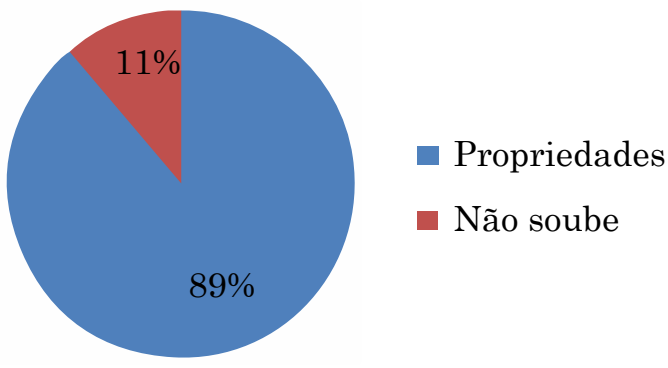

Fonte: Andrade (2017).

Gráfico 5. Respostas dos alunos quando solicitados a citar as propriedades do solo antes das aulas e práticas de ensino no Questionário 1.

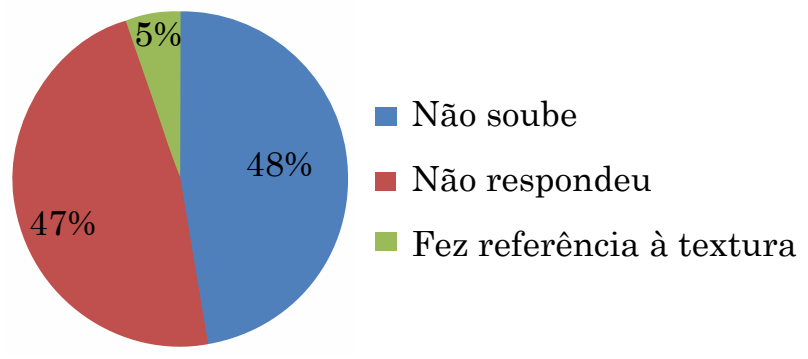

Fonte: Andrade (2017).

Analisando as respostas dos alunos, pode-se afirmar que as práticas de ensino desenvolvidas em sala sobre o "solo e suas propriedades" apresentaram resultados satisfatórios, pois contribuíram para melhorar o entendimento dos alunos sobre o assunto abordado. Estes passaram a entender o solo como camada superficial da Terra resultante de vários fatores de formação, constituído de componentes minerais e orgânicos e diferenciando-os entre si em suas propriedades. Também, torna-se evidente que a aplicação de aulas e práticas de ensino por meio de oficinas e experimentos é um método de ensino eficaz para abordar temas físico-naturais nas aulas de Geografia, especificamente na explicação dos solos, pois permite aos alunos manusear concretamente o material e observar na prática algumas propriedades do solo, sendo fundamental para a formação da consciência ambiental em relação ao uso e ocupação da terra, que se desenvolve sobre este recurso natural.

Importante destacar que "a carência de estudos mais integrados do conhecimento sobre o solo ocasiona sua degradação, principalmente, a ocorrida pelo uso e manejo agrícola, industrial e urbano" (CUNHA et al., 2013, p. 75) impróprios às condições ambientais de cada localidade, tais como a poluição e a erosão. Segundo os autores, a poluição pela acumulação de substâncias químicas e a erosão que retira, conduzem e assentam partículas de solo dos compartimentos topográficos mais altos para os mais baixos das encostas. Para melhor ocupar e manejar os solos, convém que as informações teóricas e práticas sobre a estrutura e o funcionamento dos solos na paisagem sejam repassadas à população (CUNHA et al., 2013).

Nesse sentido, Prates (2010) argumenta que o conteúdo "solos" deve ser inserido já nas séries iniciais do ensino fundamental, período propício em que a criança pode ser despertada para a importância desse recurso para o homem e o ambiente, contribuindo para que nas séries seguintes o conhecimento sobre o assunto seja aprofundado de maneira progressiva, de forma que os alunos, além de entender os aspectos de solo, adquiram bases mais sólidas sobre a inter-relação do solo com os demais elementos do meio, sua distribuição espacial, processos de formação e principais características e alguns cuidados necessários com o manejo e a conservação.

Na Base Nacional Comum Curricular de Geografia (BRASIL, 2017) a abordagem do solo aparece em unidade temática e objetos do conhecimento ao longo dos anos iniciais e finais do Ensino Fundamental, tais como: no $2^{\circ}$ ano com a habilidade de "reconhecer a importância do solo e da água para a vida, identificando seus diferentes usos (plantação e extração de materiais, entre outras possibilidades) e os impactos desses usos no cotidiano da cidade e do campo"; no $6^{\circ}$ ano com a habilidade de "relacionar padrões climáticos, tipos de solo, relevo e formações vegetais" e com a habilidade de "explicar as diferentes formas de uso do solo (rotação de terras, terraceamento, aterros etc.) e de apropriação dos recursos hídricos (sistema de irrigação, tratamento e redes de distribuição), bem como suas vantagens e desvantagens em diferentes épocas e lugares".

Para levantar discussões sobre esse conteúdo, o professor deve adotar metodologias e materiais pedagógicos que despertem o interesse dos alunos quanto à dinâmica do solo na paisagem e os levem a um posicionamento crítico frente ao processo de apropriação do espaço pelo homem (COSTA; BORGES, 2010). 
Finalmente, acredita-se que seja necessário o fortalecimento do ensino de solo nas aulas de Geografia da educação básica, com a adoção de práticas de ensino que permitam uma participação ativa dos alunos, colocando-os em contato direto com o objeto de estudo, a exemplo do desenvolvimento de oficinas e experimentos sobre os diversos conteúdos pedológicos, a fim de ampliar o conhecimento deles sobre o tema e conscientizá-los da importância da conservação deste recurso natural. Destaca-se ainda que os materiais didáticos utilizados nas oficinas desenvolvidas e apresentadas neste trabalho são de baixo custo e, mesmo sendo baratos, foram efetivos para o ensino e aprendizagem sobre o solo.

Gráfico 6. Respostas dos alunos referentes às propriedades do solo após as aulas e práticas de ensino no Questionário 2. Os números representam quantas vezes a propriedade foi citada pelos alunos.

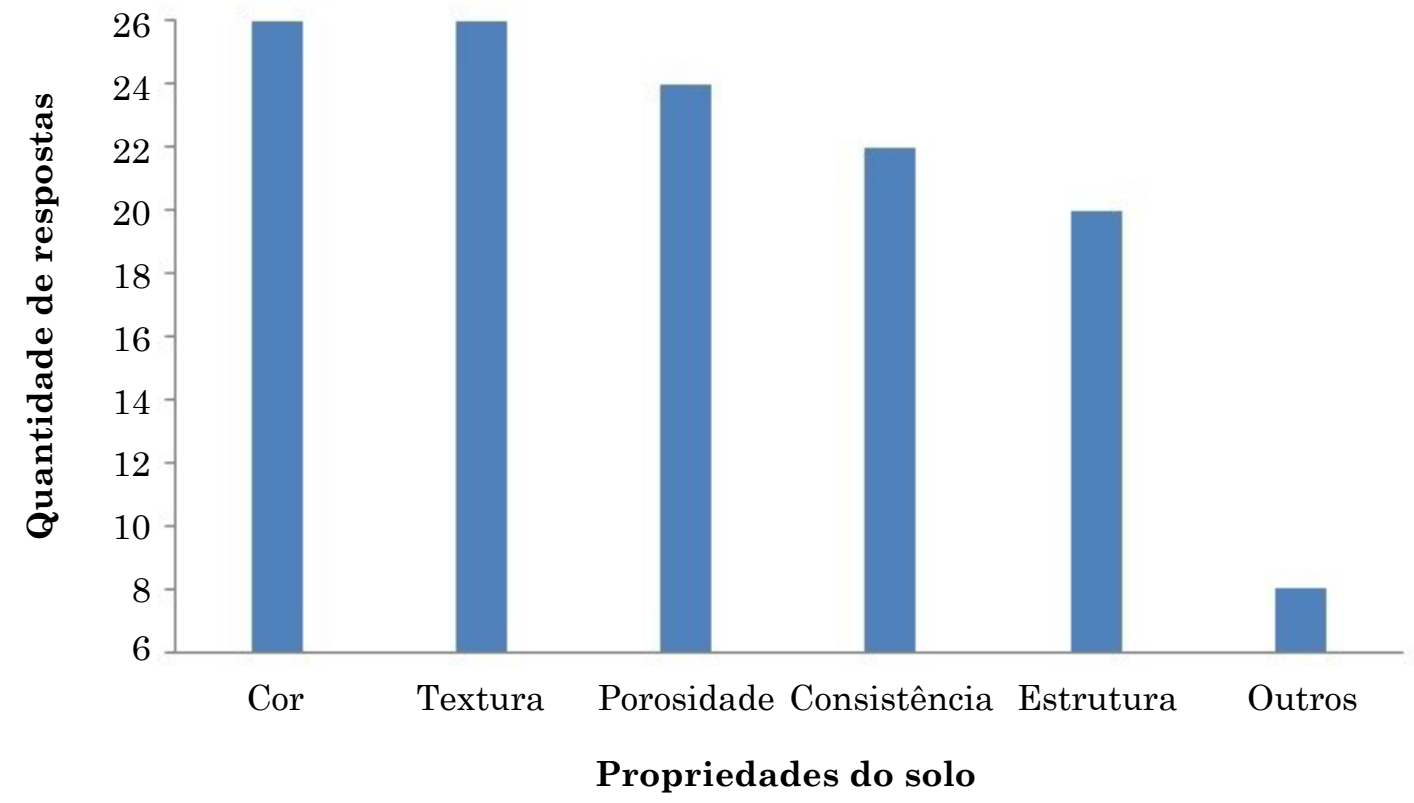

Fonte: Andrade (2017).

\section{Conclusões}

Considerando os resultados obtidos com a aplicação do questionário após as aulas e práticas de ensino sobre o solo e suas propriedades aos alunos do $3^{\circ}$ ano do Ensino Médio, apresentam-se as seguintes conclusões:

1) Os alunos demonstraram melhor entendimento do conceito de solo, ampliando a visão sobre ele. Passaram a entender o solo como camada superficial da Terra resultante de vários fatores de formação, constituídos de componentes minerais e orgânicos.

2) Os alunos compreenderam que os solos são diferentes, conseguindo diferenciá-los em algumas de suas propriedades como cor, textura e porosidade, trabalhadas nas oficinas realizadas em sala de aula.

3) A aplicação de aulas e práticas de ensino via oficinas e experimentos é um método de ensino eficaz para abordagem de temas físico-naturais nas aulas de Geografia, especificamente na explicação dos solos, pois permite aos alunos manusear concretamente o material e observar na prática algumas de suas propriedades.

\section{REFERÊNCIAS}

ANDRADE, M. L. F.; MASSABNI, V. G. O desenvolvimento de atividades práticas na escola: um desafio para os professores de ciências. Giência \& Educação, Bauru, v. 17, n. 4, p. 835-854, 2011.

BRADY, N. C.; WEIL, R. R. Elementos da natureza e propriedades dos solos. 3. ed. Porto Alegre: Bookman, 2013. 
BRASIL. Ministério da Educação. Base nacional comum curricular: educação é a base. Brasília, DF: Ministério da Educação, 2017.

CAJUEIRO, R. L. P. Manual para elaboração de trabalhos acadêmicos: guias práticos do estudante. 2. ed. São Paulo: Vozes, 2013.

CAPECHE, C. L. Educação ambiental tendo o solo como material didático: pintura com tinta de solo e colagem de solo sobre superfícies. Rio de Janeiro: Embrapa, 2010.

\section{CAVALCANTI, L. S. Geografia e prática de ensino.} Goiânia: Alternativa, 2002.

COSTA, A. A; BORGES, V. G. Brincar, criar e aprender: a Geografia e o ensino de solos em cores, textura e arte. In: MORAIS, E. M. B.; MORAES, L. B. Formação de professores: conteúdos e metodologias no ensino de Geografia. Goiânia: Nepeg, 2010. p. 137-154.

GUNHA, J. E. et al. Práticas pedagógicas para ensino sobre solos: aplicação à preservação ambiental. Terra e Didática, Campinas, v. 9, n. 2, p. 74-81, 2013.

DAS, B. M. Fundamentos de Engenharia Geotécnica. São Paulo: Thomson, 2007.

\section{EMBRAPA - EMPRESA BRASILEIRA DE} PESQUISA AGROPEGUÁRIA. Sistema Brasileiro de Glassificação de Solos. Rio de Janeiro: Embrapa, 2013.

EMBRAPA - EMPRESA BRASILEIRA DE PESQUISA AGROPEGUÁRIA. Relatório da FAO com participação da Embrapa revela que 33\% dos solos do mundo estão degradados. In: Embrapa.br. Rio de
Janeiro, 7 dez. 2015. Disponível em: https://bit.ly/2ANVhh1. Acesso em: 11 fev. 2020.

KER, J. C. et al. Pedologia: fundamentos. Viçosa, MG: SBCS, 2012.

LEPSCH, I. F. Formação e conservação do solo. São Paulo: Oficina de Textos, 2002.

LEPSCH, I. F. 19 lições de pedologia. São Paulo: Oficina de Textos, 2011.

LIBÂNEO, J. C. Didática. São Paulo: Cortez, 1994.

MACANHÃO, P.; LIMA, M. R. Experimentoteca de solos/UFPR. In: UNIVERSIDADE FEDERAL DO PARANÁ. Departamento de Solos e Engenharia Agrícola. Programa Solo na Escola. Curitiba: UFPR, 2005. Disponível em: https://bit.ly/2LN0dot. Acesso em: 10 out. 2017.

PRATES, R. Análise da abordagem do solo no Ensino Fundamental: situação e proposições: uma proposta inovadora. 2010. Trabalho de conclusão de curso (Bacharelado em Geografia) - Universidade Federal do Rio de Janeiro, Rio de Janeiro, 2010.

RESENDE, M. et al. Pedologia: base para distinção de ambientes. 5. ed. Lavras: Ufla, 2007.

VENTURI, L. A. B. Praticando a Geografia: técnicas de campo e laboratório. São Paulo: Oficina de Textos, 2009.

YOSHIOKA, M. H.; LIMA, R. L. Experimentoteca de solos: porosidade do solo. Curitiba: UFPR, 2017. Disponível em: https://bit.ly/3bP1AO3. Acesso em: 12 out. 2017. 